\title{
DESCENTRALIZAÇÃO E SAÚDE NO BRASIL: ALGUMAS REFLEXÕES PRELIMINARES
}

\section{Paulo Eduardo Elias*}

RESUMO: O presente artigo trata de aspectos relacionados ao processo de descentralização da saúde como vem sendo implementado no Brasil. Inicialmente busca relacionar alguns tópicos considerados pelo autor como preliminares para balizar a discussão acerca do caso brasileiro na descentralização da saúde. Num segundo momento procedeu-se a uma rápida recuperação da trajetória da descentralização da saúde no Brasil, abarcando desde os seus primórdios no início da década de 70 até sua plena operacionalização com a Norma Operacional Básica 01 editada em 1993. A esta breve recomposição da descentralização na saúde incorpora-se uma discussão critica sobre os aspectos mais relevantes desta trajetória. Por fim o artigo aponta alguns constrangimentos presentes na descentralização da saúde como vem sendo implementada no Brasil.

Palavras-chave: descentralização da saúde, caminhos da descentralização da saúde, saúde no Brasil, implementação, Reforma Sanitária

- Docente do Departamento de Medicina Preventiva da Faculdade de Medicina da USP e pesquisador do Centro deEstudos de Cultura Contemporânea (CEDEC). E.Mail: pemelias@usp.br 


\section{INTRODUÇÃO}

É da vinculação com a temática do Estado, principalmente das relativas à sua organização, que derivam as principais caracteristicas que compõem os diferentes aspectos através dos quais a descentralização ganha concretude. Em primeiro lugar, deve-se apontar a existência de uma relação interativa entre descentralização e centralização, em que, como ensina Roversi-Monaco, estes dois ordenamentos não existem em estado puro, pois uma dada descentralização requer algum grau de centralização para manutenção das funções do Estado moderno. Ao contrário disto, segundo este autor, a adoção da concepção de antagonismo ou excludência entre esses dois ordenamentos, o que corresponderia a uma situação de radicalização da descentralização, implica a ruptura da noção de Estado. Já a consideração de seu oposto, ou seja, a da centralização total, mostra-se inviável frente à imensa gama de finalidades e funções que se exige do Estado moderno. Ainda segundo este mesmo autor, "o único caminho para uma transformação é, portanto, o de um movimento gradual e progressivo dirigido a abrandar aquelas tendências que, num ou noutro sentido, tenham sido julgadas em desacordo com a realidade efetiva" (BOBBIO,MATTEUCCI,1993) Dito de outro modo, a descentralização também sempre pressupõe alguma atribuição ou poder centralizado a ser transferido, disto decorrendo que uma esfera de governo abra mão de poder, de prerrogativas ou de equipamentos, em benefício de outra de menor abrangência. $A$ iniciativa desta transferência pode ser exclusivamente unilateral, isto é, da instância detentora em direção à beneficiária, ou pode se dar de forma negociada entre as duas instâncias. Desta forma, não pode existir autonomia total da esfera local na hipótese da manutenção do Estado e na vigência do princípio federativo (ALMEIDA,1995). Por analogia ao que afirma LOBO (1995) ao tratar da racionalização do gasto, aqui também cabe advertir sobre a "necessidade de revisão ou retomada do pacto federativo": uma estrutura federativa como a nossa supõe a atuação decidida das três esferas de poder, com competências distintas, mas articuladas entre si. Com isto introduz-se o tema da 
negociação entre as esferas de poder no tratamento da autonomia, fator indispensável para se levar a bom termo a transferência de poder decisório mas, em nosso meio, freqüentemente relegado a segundo plano. Como adverte ALMEIDA (1995) há falta de uma política de descentralização pactuada entre as esferas públicas.

Assim, supõe-se que a adoção parcial ou integral desses requisitos exerce forte influência sobre o processo de descentralização em termos de seu desenvolvimento, mas sobretudo da sua eficiência e eficácia social. Neste sentido, deve-se esperar muito poucos resultados de um processo de descentralização imposto unilateralmente por uma das partes. Como afirma TOBAR(1991:41), ao tratar dos consensos expressos pela literatura especializada, "não se acredita numa descentralização feita por decreto". Assim, às clássicas diretrizes tais como as propostas por LOBO(1995) deve-se agregar um outro critério na condição de pressuposto: trata-se da negociação política entre as partes envolvidas de modo a configurar um processo de descentralização pactuado. Disto intui-se que a vigência deste quesito na implementação da descentralização é fundamental para o adequado desenvolvimento daquelas diretrizes, sem o que não há como efetivá-las no processo de descentralização, sobretudo no que se refere à transparência das decisões e ao controle público.

A descentralizaçăo assim concebida implica necessariamente em transferência de poder decisório associado aos recursos mínimos necessários para garantir o seu exercício concreto.

Já a transferência de poder político para as esferas de poder mais próximas aos cidadãos cria inúmeras possibilidades para uma ampliação da representação, em que aos clássicos mecanismos da democracia representativa, como por exemplo o voto universal e o Parlamento, podem ser agregados aqueles da democracia direta, trazendo assim significativos ganhos para o exercício político, alçando-o a um patamar superior. 
Isto tudo devido, principalmente, às inúmeras vantagens que os mecanismos de democracia podem propiciar, dentre eles:

- $\quad$ incremento do grau de envolvimento dos cidadãos na discussão dos problemas e na busca das soluções;

- a possibilidade da criação de novos direitos e a cobrança da efetivação daqueles subtraídos aos cidadãos;

- o aumento do grau de informações sobre os problemas sociais bem como sobre o funcionamento do sistema político e administrativo como um todo;

- a politização das demandas sociais, no sentido da sua generalização enquanto necessidades socialmente construídas, elevando-as à condição de direitos sociais, estes últimos elementos indispensáveis para a formulação e implementação de politicas de corte transformador;

- o compromisso com os resultados do ponto de vista da satisfação das demandas sociais, o que resulta em melhoria da eficácia social do Estado;

- o incremento do grau de conscientização social e política.

\section{REQUISITOS DA DESCENTRALIZAÇÃO}

Um estudo mais detalhado da produção corrente sobre descentralização mostra, de imediato, a enorme gama de divergências entre os diversos autores sobre esse tema. Tais discrepâncias não se devem apenas às diferenças de perspectivas teóricas ou metodológicas, embora se reconheça sua ocorrência que advém, sobretudo, da enorme complexidade que cerca o tema da descentralização, podendo ela ocorrer sob uma grande variedade de formas e matizes, por vezes constituindo um processo de idas e vindas. Conseqüentemente, torna-se extremamente trabalhosa e mesmo 
desafiadora a tarefa de sintetizar essa amplitude de situações e variações num enunciado único, preciso e mais ou menos conciso, e que possa dar conta, de maneira adequada, desse universo.

LOBO (1995) indica o que considera serem as diretrizes clássicas dos processos de descentralização: a flexibilidade, o gradualismo, a transparência no processo decisório e o controle social. A palavra "clássicas" parece ser aí empregada pela autora no sentido de indicações ideais para a adequada consecução dos objetivos em qualquer processo de descentralização, não significando que, de um lado, frente a situações de realidade devam todas estar sempre presentes e, de outro, que cada uma delas seja imune à apropriação ideológica por parte de distintos setores, o que pode acabar por Ihes conferir sentido diverso.

É também LOBO (1995) quem aponta para a perenidade temporal do movimento descentralizador quando se assegura sua conformação como uma política de Estado, e deste modo "ter-se-ia a garantia de continuidade e consolidação de um processo que pode ter um início, mas que dificilmente se visualiza o seu fim".

Quanto ao processo mais radical de descentralizaçăo, ele comporta pelo menos duas modalidades em sua implementação: a etapista, apresentando um curso mais lento e gradual, ainda que não necessariamente linear, e a outra, ocorrendo de uma só vez ou numa única etapa, configurando-se, em contraposição à anterior, um processo de tipo unicista ou imediatista.

No primeiro caso, usualmente vinculado à situações em que ocorre transferência de poder, inicialmente privilegia-se a dimensão administrativa, explorando toda sua potencialidade, para só depois se voltar para as outras dimensões - a política e a financeira -, estas duas qualificadoras do grau de efetividade da descentralização. No caso da descentralização em etapa única, geralmente inicia-se pelas dimensões política 
e financeira, provendo-se seus principais elementos, de modo a garantir à instância periférica a correspondente autonomia política e financeira, sucedidas pela autonomia administrativa.

A escolha racional de qualquer dessas duas possibilidades prende-se minimamente a uma análise preliminar dos possiveis efeitos da descentralização sobre as ações estatais que se pretende descentralizar, o que termina por envolver a avaliação das condições da instância beneficiária da descentralização, destacando-se a capacitação técnica e operacional para manter as ações e os șerviços descentralizados (as condições técnico-administrativas) e as circunstâncias politicas referidas, tanto à conservação de um certo equilibrio entre as esferas de governo e, quanto à manutenção de um grau mínimo de sustentabilidade e estabilidade política dado o sistema político vigente.

Assim concebido, o processo de descentralização comporta pelo menos três principais dimensões: política, econômica, e administrativa.

Na situação brasileira, sobretudo em relação ao Sistema Único de Saúde (SUS), os defensores da descentralização dividem-se entre esses dois grandes grupos: os etapistas/gradualistas ou mediatistas e, os unicistas ou imediatistas. O primeiro grupo ainda subdivide-se entre aqueles que defendem que o processo abarque todas as dimensões da descentralização e aqueles que advogam apenas a desconcentração, ou seja, um processo imune à transferência de poder politico e financeiro de modo a manter a esfera local submetida às demais. Para alguns que pertencem a este grupo, a desconcentração é condição necessária mas não suficiente para a descentralização, uma vez que representa a etapa inicial do processo de descentralização, ainda que este não possa ser reduzido àquela.

Um outro ângulo ainda a ser examinado decorre de alguns elementos comuns subjacentes às diversas definições de descentralização, dentre elas a existência 
de certo grau de concordância sobre a necessidade de se fortalecer a esfera local. Como já referido, os meios para atingir este objetivo referem-se basicamente às transferências de algum tipo de poder decisório, ou de ação estatal, ao poder local, o que demanda deste capacitação de várias ordens, como por exemplo técnica, financeira, administrativa, gerencial, entre outras, para que ele possa arcar com aquelas transferências sem que isso implique em perdas de capacidade de resposta às necessidades sociais. Desta ótica a descentralização exige pré-requisitos do nivel local para sua efetivação; e mais, mesmo na inexistência destas, a esfera central encontra-se comprometida com a local, no sentido do provimento do auxilio necessário para obtenção desses requisitos.

Ademais disso, duas questões derivadas do fortalecimento do poder local merecem ser mencionadas: a incorporação no sistema político de organizações da sociedade civil, e a escolha segundo determinados critérios das ações estatais a serem descentralizadas. No primeiro caso trata-se da operacionalização de mecanismos de participação, tais como os conselhos consultivos e conselhos gestores de serviços, e os possiveis riscos que os cercam, entre eles, o da cooptação política e o da dominância de interesses corporativos nos espaços voltados para as questões da coisa pública.

Um último aspecto deve ser considerado a partir do ponto de vista dos atributos necessários para se lograr os resultados desejados no processo de descentralização. Como aponta TOBAR(1991), deve-se reconhecer nas ações administrativas as possibilidades de prevalecerem a eficácia e a eficiência'na implementação da descentralização.

Por tudo o que foi dito até aqui, pode-se depreender que a noção de descentralização não é muito bem estabelecida, sobretudo na sua aplicação ao campo da saúde. Não obstante a área da saúde é considerada como o exemplo mais consolidado da descentralização encetada pelo Estado brasileiro em período recente. 


\section{A DESCENTRALIZAÇÃO NA SAÚDE}

É também o setor saúde aquele que sofre significativa reforma no padrão de intervenção pública na década de 80 , decorrente das novas exigências colocadas ao Estado brasileiro, conseqüência das mudanças ocorridas na economia mundial.

Por conseguinte, a relativa disponibilidade de recursos públicos para o financiamento da saúde vigente até fins dos anos 70 - boa parte deles empregados na capitalização do setor privado de saúde através de medidas de extensão de cobertura e de seletividade da universalização, da assistência médica, restrita basicamente às regiões metropolitanas - é substituída pela necessidade de contenção geral dos gastos públicos subjacente às crises fiscal do Estado e financeira da previdência, ambas decorrentes, principalmente, da desaceleração da atividade econômica.

Deste modo, impõem-se ao Estado este novo padrão de intervenção pública, e que se traduz no setor saúde, num primeiro momento, na contenção de despesas e maximização da utilização dos equipamentos, no sentido de promover a racionalização das ações, agregando-se, posteriormente, o ideário da descentralização e as medidas dela decorrentes.

Não obstante a discussão acerca da repartição do poder político entre as esferas de governo e conseqüentemente da questão municipal vir de longa data, a utilização recorrente do termo descentralização é bem mais recente, remontando no plano internacional à década de 60 , diante dos primeiros sinais da crise que se abateria sobre os vários modelos de Welfare State, enquanto no plano nacional manifesta-se em fins da década de 70 , sobretudo nas áreas tributária e administrativa, a partir do "movimento municipalista" , e através deste penetrando lentamente no setor saúde até ganhar maior expressão no início dos anos 80 , com o advento das Ações Integradas de 
Saúde (AIS), que por sua vez ocorre no bojo de uma crise financeira previdenciária e da crise do regime político autoritário vigente.

$\mathrm{Na}$ área da saúde não é tarefa simples precisar o momento em que o termo descentralização começa a ser utilizado de modo mais recorrente e substantivo; no entanto, certamente a descentralização como processo começa a ganhar corpo em meados da década de $70 \mathrm{com}$ a conquista de alguns poucos governos municipais pela oposição, à época politicamente identificada pelo Movimento Democrático Brasileiro (MDB). Assim, segundo MÜLLER NETO (1991), a partir de meados da década de 70 o setor saúde de algumas prefeituras governadas pela oposição, dentre elas a de Campinas (SP), Lages (SC), Londrina (PR), Niteroi (RJ), e Piracicaba (SP), implementa modelos alternativos na produção de serviços de saúde, centrados na atenção primária.

$\mathrm{Na}$ atualidade, frente à absolutização da imagem de caos no sistema de saúde apresentada à sociedade, com o destaque e a ênfase nos diversos meios de comunicação para as fraudes e os desperdícios financeiros, o termo descentralização tem sido evocado, no plano retórico e no da ação, como a melhor alternativa para produzir o necessário ajuste do Estado no setor, e promover a melhoria da racionalidade do sistema de saúde. Assim o defende as diferentes forças politicas envolvidas no processo de descentralização da saúde, compartilhando argumentos semelhantes para realçar os melhores atributos da esfera local, qualificados pela maior proximidade governante/ governados, pela menor complexidade administrativa, pelo menor grau de burocratização, e pela maior capacidade para fiscalizar e prover os serviços de saúde. Do mesmo modo, estas manifestações repercutem no debate social em geral, e na midia em particular,

\footnotetext{
'Articulação informal entre Prefeitos Municipais, principalmente os pertencentes ao MDB, em torno da questão de uma Reforma Tributária favorável aos Municípios. Ver: Muller-Neto (1991, p.58)
} 
gerando expectativa e transformando os municipios em únicos depositários da cruzada contra as fraudes e os desvios existentes no sistema de saúde, tributários de um enorme clamor público que nele identifica em grande medida as dificuldades do seu cotidiano em relação aos serviços de saúde.

Ainda que esses atributos possam ser encontrados, em maior ou menor grau, nos municípios de médio e grande portes, e se considerando a manutenção da perspectiva do processo de descentralização em curso restrita apenas à lógica do financiamento diante dos desvios financeiros disseminados no Sistema de Saúde, configura-se uma situação que mais do que nunca exige a implementação deste processo em moldes a contemplar ganhos concretos aos municipios, sem o que as fraudes continuarão vicejando com a mesma importância social que apresentam sob a pressão moral exercida ao município no sentido de que cumpra a função de coibir as defraudes e os desvios financeiros. Isto por uma simples razão: os recursos a serem fiscalizados, não obstante sejam de natureza pública, não provêm dos cofres municipais. A despeito, portanto, de todas as restrições de ordem moral e ética pertinentes de serem formalizadas, os governos locais só se sentirão comprometidos com sua fiscalização em moldes mais eficientes na medida em que recebam uma compensação equivalente à mesma lógica que permeia todo o sistema, ou seja, de ordem estritamente financeira. Caso contrário, sobrarão os argumentos e as pressões morais quase sem nenhum resultado em termos práticos. Saliente-se que tais atribuições devam ser função de toda e qualquer esfera de governo e não apenas do nivel local; por mais que ele disponha de melhores condições para executá-la, o processo de descentralização não deve se restringir apenas a estes aspectos, sob pena de resultar em grande frustração se medidas de caráter estrutural, tais como a referida compensação, não forem introduzidas em benefício da suposição da existência de uma ética da solidariedade e da promoção de um dever público que infelizmente ainda não estão suficientemente disseminadas pela sociedade brasileira $\mathrm{e}$ tampouco nas relações entre as esferas governamentais. A este respeito, CASTRO 
(apud SATO,1993) aponta para "uma forte tendência à setorialização da politica de saúde e não a sua integração ao nivel territorial, (...) favorecendo o fortalecimento de corporativismos locais em disputa por recursos públicos e pelo monopólio dos convênios, ...".

De outra perspectiva , o surgimento do Sistema Único de Saúde (SUS) na conjuntura social e politica permeada pelos trabalhos da Assembléia Nacional Constituinte, encerra duas contradições que irão perdurar nos anos subseqüentes, repercutindo de forma acentuada em sua operacionalização. A primeira, de fundo constitucional, decorre do fato de a Seção Saúde da Constituição ser a úniça a enunciar claramente a diretriz da descentralização, não obstante esta orientar boa parte da Constituição. Saliente-se que a intenção inicial dos Constituintes era a de manter a responsabilidade dos municípios apenas para as ações básicas de saúde, assim como previsto no Sistema Unificado e Descentralizado de Saúde (SUDS), formulação esta que perdurou durante todo o desenrolar dos trabalhos constituintes, constando inclusive do Projeto de Constituição e do Substitutivo a ele apresentado pela Comissão de Sistematização (VIANNA, 1991). O texto aprovado, possibilitando a transferência de ações e serviços para a esfera local, tal como consta do Artigo 30 que trata das competências dos Municipios, inciso VII - " prestar, com a cooperação técnica e financeira da União e do Estado, serviços de atendimento à saúde da população" (BRASIL,1988) -, só foi incluído durante a fase de aprovação final do texto constitucional, após intenso processo de negociação política para viabilizá-lo.

Contudo, ao estudar os impactos das mudanças constitucionais nas áreas sociais, Barros e Silva (1995) além de identificar apenas o setor saúde como aquele submetido a uma política ativa de descentralização, relativiza seus beneficios com a afirmação de que "no entanto, o agravamento dos problemas de financiamento setorial evidenciou as questões e as dificuldades de relacionamento entre distintas esferas de 
governo e entre estas e o setor privado prestador de serviços, comprometendo os resultados positivos do processo ...".

Agregue-se $a$ isto o fato de se estimar em pelo menos $50 \%$ os municípios que não têm condições financeiras e administrativas próprias para subsistirem como esfera autônoma de governo, o que implica a sua dependência das esferas estadual e federal para manter seus compromissos financeiros e administrativos, vendo assim diminuidas suas prerrogativas enquanto poder local, sobretudo em relação à sua autonomia.

Ainda no que toca à situação mais específica dos municípios, principalmente daqueles de médio e grande portes, a estas questões agregam-se uns tantos outros tópicos, entre os quais se destacam:

- o gerenciamento do setor privado contratado;

- a superação no nível dos serviços da concepção dicotomizada entre ações curativas e preventivas de modo a se realocar a prática médica individual às necessidades de saúde da população abrangida pelo serviço;

- a introdução do Planejamento em Saúde diferenciado segundo as necessidades de grupos populacionais definidos geograficamente em um distrito de saúde;

- desenvolvimento de políticas de Recursos Humanos centradas nos principios da profissionalização, da participação e da humanização dos serviços;

- desenvolvimento de projetos de avaliação continuada dos serviços como instrumento de subsídio para o Planejamento da atenção à saúde.

Mesmo contando com as diretrizes e o arcabouço jurídico minimamente 
estabelecidos, foram necessários quase 5 anos da vigência da Constituição, e 3 da aprovação da Lei Orgânica da Saúde, para que o Governo Federal desse passos mais firmes na implementação da descentralização da saúde, procedimento este conhecido como "Municipalização da Saúde". O instrumento fundamental para alavancar este processo foi a Norma Operacional Básica, SUS 01/93 (NOB), aprovada pela Portaria $n$. 545 do Ministério da Saúde. A NOB "regulamenta o processo de descentralização da gestão dos serviços e ações no âmbito do Sistema Único de Saúde e estabelece os mecanismos de financiamento das ações de saúde, em particular da assistência hospitalar e ambulatorial, e as diretrizes para os investimentos no setor" (BRASIL,1993).

A proposta de descentralização contida na NOB é audaciosa, no sentido de buscar dar conta de variados e complexos aspectos, tais como o modelo assistencial, a redefinição de competências das esferas de governo, e a questão dos recursos humanos, dentre outros. No entanto, em seu detalhamento operativo podem-se identificar dois pilares fundamentais: o financiamento das ações de saúde e o controle social. Assim, a constituição e o funcionamento pleno dos Fundos e dos Conselhos de Saúde são requisitos indispensáveis para que Estados e municipios se candidatem à descentralização.

Segundo VIANNA (1991) é necessário a assunção de uma série de pressupostos para que se implemente uma descentralização que preserve minimamente a autonomia das esferas mais periféricas:

- a responsabilidade compartilhada entre as esferas de governo em relação à saúde da população;

- a obrigatoriedade da presença de fontes federais no financiamento da saúde concomitante à adoção de mecanismos que visem os aspectos redistributivos;

- a exigência em se adotar o automatismo e a o critério da eqüidade nos 
repasses financeiros;

- a efetivação da transferência centrifuga de poder decisório, de modo a conferir ao nivel local um "âmbito de governabilidade ampla", possibilitando a condução da política de saúde;

- o deslocamento do poder para as esferas mais periféricas se justifica sobretudo pela participação do usuário na gestão;

- a realização das mudanças Constitucionais necessárias de modo a permitir o automatismo da transferência e a liberdade no uso dos recursos por parte das instâncias recipientes;

- a divisão de funções entre as esferas de governo envolve a retirada do Ministério da Saúde da prestação direta de serviços de natureza local;

- abolir as transferências negociadas dos recursos para custeio, estabelecendo-se o automatismo dos repasses e aplicando-se critérios claros e objetivos para sua distribuição;

- a dotação como meta realista a ser perseguida até o final da década a municipalização dos serviços de saúde nas localidades com mais de 50 mil habitantes;

- a superação da fragilidade política do movimento pela descentralização dar-se-á a partir do momento em que o conjunto dos usuários estiver convencido de sua potencialidade como estratégia para viabilização de suas aspirações;

\section{CONSTRANGIMENTOS À DESCENTRALIZAÇÃO}

Nesses novos termos, impõem-se pelo menos três ordens de questões, a seguir brevemente tratadas. Inicialmente uma, passivel de generalização a qualquer processo de descentralização, e que diz respeito a alguns pressupostos, dentre eles de 
que a esfera municipal de governo seja mais democrática por estar mais próxima da população, e que as autoridades locais detém melhor conhecimento das necessidades dos munícipes. No caso brasileiro, ambas as afirmações carecem de estudos mais aprofundados embasados em comprovações empíricas. Ademais, há que se indagar sobre a capacitação técnica da esfera local para exercer as atribuições que the são conferidas, ao pretender-se uma descentralização que preserve um mínimo de eficácia social, isto é, que responda de modo socialmente competente às demandas da população.

A segunda, refere-se à excessiva indefinição das atribuições especificas de cada esfera de governo. Fato que tem revelado graves repercussões gerenciais e administrativas, chegando a tolher a possibilidade do agravo judicial ao dificultar a manifestação do Judiciário sobre a definição de certas responsabilidades, bem como políticas, em particular no que diz respeito ao desenvolvimento de canais voltados para o controle público do Estado.

A última das questões diz respeito aos aspectos relacionados ao financiamento, seja do ponto de vista da escassez de recursos, seja do ponto de vista da qualificação do tipo de financiamento. Assim, mesmo da perspectiva de uma descentralização alicerçada na transferência de recursos financeiros sua plena viabilidade depende não só do montante financeiro que faça frente aos compromissos assumidos, mas também da regularidade do financiamento e da capacidade de aumento de recursos das três esferas de governo destinados ao setor. Ademais, a relação entre esferas de governo pautada em mecanismos como o pagamento por serviços prestados e 0 instrumento convênio estreita ainda mais as possibilidades de essa descentralização ser capaz de minimamente responder às necessidades administrativas e gerenciais do nível municipal. Além de tudo isto, a natureza do tipo de financiamento, com pequena participação dos recursos fiscais, obstaculiza seriamente a efetivação dos preceitos constitucionais da universalização, da eqüidade e da igualdade. 


\section{CONSIDERAÇÕES FINAIS}

Não obstante o setor saúde se constituir num exemplo relativamente solitário de implementação da descentralização na área social, este processo efetivamente implementado há apenas três anos apresenta constrangimentos e vicissitudes de ordens e alcances variados.

Vale destacar, dentre aqueles de relevância mais estrutural, a origem dos recursos empregados no financiamento da saúde, o caráter do sistema federativo brasileiro marcado pela ausência de mecanismos efetivos de cooperação entre as esferas de governo, a indefinição entre os diferentes niveis de governo no que concerne às atribuições na área da saúde, a tradição centralizadora do Estado brasileiro e sua repercussão no estamento burocrático federal e a situação financeira, administrativa e politica de significativa parcela dos municipios que os coloca em situação de extrema dependência das outras esferas de poder, inabilitando-os, assim, técnica e administrativamente como beneficiários de uma efetiva descentralização da saúde.

Não obstante as potencialidades que a descentralização possa apresentar, o processo em curso na saúde se configura, de certo modo, como algo que está por se fazer. Em conseqüência uma descentralização que busque enfrentar a exclusão de imensos segmentos da população com eficácia social - de longe um dos problemas de maior relevância para o país -, deve pautar-se pela flexibilização e adequação à heterogeneidade de situações que se apresentam nas regiões brasileiras. Isto implica na exclusão de dogmatismos e principismos na condução desse processo, implementadoo de modo a contemplar e estimular a negociação entre as esferas de governo, prevendose a criação de novos instrumentos jurídicos legais para sua sustentação e que seja perseguido como uma política de Estado, isto é aquela intervenção estatal de longo curso perpassando o periodo de diversos governos. 
Deste modo, estariamos dando passos que, creio, sejam significativos no enfrentamento dos desafios presentes, mas com os olhos postos no futuro.

\section{REFERÊNCIAS BIBLIOGRÁFICAS}

ALMEIDA, M.H.T. de Federalismo e politicas sociais. Rev. Bras. Ciênc. Soc., 28:87108, 1995.

BARROS e SILVA, P.L. Descentralização de políticas sociais: marco teórico e experiências internacional e brasileira. In: Velloso, J.P.R.; Albuquerque, R. C.; Knoop, J. coord. Políticas sociais no Brasil: descentralização, eficiência e eqüidade. Rio de Janeiro, Inae/lldes, 1995.

BOBBIO, N. Dicionário de politica. 5a. ed. Brasilia, Editora Universidade de Brasilia, 1993.

BRASIL. Senado Federal Constituição: República Federativa do Brasil. Brasilia-DF; , Centro Gráfico, 1988.

LOBO, T. Politicas sociais no Brasil: descentralização para mais eficiência e eqüidade. In: Velloso, J.P.R.; Albuquerque, R. C.; Knoop, J., coord. Políticas sociais no Brasil: descentralização, eficiência e eqüidade. Rio de Janeiro, Inae/lldes, 1995.

MINISTÉRIO DA SAÚDE. Sistema Único de Saúde. Descentralização das ações e serviços de saúde: a ousadia de cumprir e fazer cumprir a lei; Brasilia, 1993.

MÜLLER-NETO, J. Políticas de saúde no Brasil: a descentralização e seus atores. Saúde em Deb., 31:54-66, 1991.

SATO, A.K. Descentralização: um tema complexo. Texto para discussão n 314 , Brasília, Ipea

TOBAR, F. O conceito de descentralização: usos e abusos. Plan. Pol. Pública, 5: 31-51, 1991. 
VIANNA, S. M.; PIOLA, S.F.; GUERRA, A.J.; CAMARGO, S.F. O financiamento da descentralização dos serviços de saúde: critérios para transferências de recursos federais para estados e municípios. Brasília, IPEA, 1991. (Documento de Política, n. $3)$.

SUMMARY: The present article deals with issues related to the process of the on going implementation of health decentralisation in Brazil. Firstly it lists some topics seen as preliminary by the author for the establishment of grounds for the discussion of that process. Next it briefly outlines the trajectory of health decentralisation in Brazil from its origin in the early 70s until its full implementation with the 1993 Norma Operacional Básica 01 . This outline is followed by a critical discussion on the outstanding points of the trajectory. The article finally points a few constraints present in the health decentralisation taking place in Brazil.

Key words: ways of health decentralisation, health decentralisation, implementation, sanitary reform 